UDK 78:7.038.543

Alenka Barber-Keršovan

Inštitut za muzikologiijo Univerze v Hamburgu

Institut für Musikwissenschaft, Universität, Hamburg

\title{
"Internet Killed the Video Star?"1 Vizualna glasba med teorijo, tehnologijo, mediji in estetiko
}

\author{
"Internet Killed the Video Star?" \\ Visual Music between the Theory, Technology, \\ Media and Aesthetics
}

Ključne besede: vizualna glasba, teorija, tehnologija, mediji, estetika glasbe

\section{IZVLEČEK}

Članek v grobih potezah skicira razvoj vizualizacije glasbe, ki je v osemdesetih letih prejšnjega stoletja vodila $\mathrm{k}$ etabliranju videoklipa kot samostojne estetske oblike ter glasbene televizije (MTV) kot specializiranega medija za ta glasbeni žanr. Omenjeni razvoj obravnava v kompleksnem odnosu med teoretičnimi predpostavkami, estetskimi konvencijami ter tehnološkimi in distribucijskimi možnostmi. Videoklip predstavlja posebno na področju popularne glasbe še vedno pomembno izrazno sredstvo in marketinško strategijo, ceprav se z digitalno tehnologijo in internetom pojavljajo tudi nove oblike glasbene komunikacije in audio-vizualne ustvarjalnosti.
Keywords: visual music, theory, technology, media, aesthetics of music

ABSTRACT

In this article a short historical sketch of the visualisation of music is offered, which led in the 1980ies to the establishing of the video clip as an independent aesthetic form and the music television (MTV) as a specialized medium for this musical genre. The development mentioned is discussed in a complex relationship between theoretical prepositions, aesthetic conventions and technological and distributional possibilities. Currently, especially in popular music video clip still represents an important form of musical expression and marketing strategies, though with the digital technology and the internet new forms of musical communication and audio-visual creativity are coming up. 


\section{Pomenski naboj pojma video}

Pojem 'video' pomeni dobesedno 'vidim'. Prvotno so z njim označevali elektronski postopek snemanja in predvajanja vizualnega in akustičnega materiala, kot so ga 1948 razvili v interne namene televizijske produkcije. Kasneje se je ta izraz navezoval na dva komplementarna aparata, na video kamero in videorekorder. Po letu 1962 so video kamero pričeli uporabljati tudi izven televizijskih hiš, sprva v svrho nadzorovanja prometa, javnih ustanov in nakupovalnih centrov (prim. Uka, 1994, s. 333), kasneje pa tudi v individualne namene v smislu zabavne elektronike. V začetku osemdesetih let je bila ta lahko upravljiva tehnologija zadovoljive kvalitete dostopna tudi množičnemu potrošniku in mu omogočila privatno in individualno rokovanje $\mathrm{z}$ audio-vizualnimi vsebinami (Uka, 1994, s. 345-346).

Paralelno s kamero je šel razvoj videorekorderja, ki omogoča snemanje in reprodukcijo televizijskih oddaj v časovnem zamiku ter predvajanje najrazličnejših vsebin, od (lastno posnetih) filmov preko napotkov za rokodelce do pedagoških programov. Nadaljnji člen video tehnologije je video sintesajzer. Le-ta omogoča linearno povezavo slike in tona ter uporabo različnih efektov in predstavlja zato prav tako nepogrešljivo oblikovalno sredstvo kot glasbeni sintesajzer na področju glasbene komunikacije.

Možnosti video tehnologije so pogojile tudi specifično estetsko produkcijo. Avantgardisti Bazon Brock, Joseph Beuys s svojo „Filz TV” in Nam June Paik, ki je v instalaciji „Exposition of Music - Electronic Television" predstavil 12 elektronsko manipuliranih televizijskih sprejemnikov, so že v šestdesetih letih prejšnjega stoletja etablirali video art kot samostojno umetniško zvrst (prim. Lampalzer, 1992). Čeprav so pri prvih projektih s tega področja sodelovale tudi nekatere televizijske postaje, so njihova dela nihala med fascinacijo in kritično refleksijo tega množičnega medija. Pri tem so se pogosto sklicevali na razglabljanje kanadskega teoretika Marshalla McLuhana, ki je svojo pesimistično vizijo medijske prihodnosti predstavil v večih knjigah. Pri tem je zagovarjal tezo, da množični mediji spreminjajo svet v 'globalno vas', v kateri se prostorske in časovne dimenzije izničujejo in se medijska vsebina reducira na formalno obliko: 'the medium is the message' (prim. McLuhan, 1995). Nam June Paik, ki je med drugim tudi aktivno sodeloval pri razvoju videosintesajzerja (prim. Lampalzer, 1992, s. 33), je to krilatico tematiziral v svojem delu „The Medium is the Medium".

Poleg video arta, ki korenini v slikarstvu, poznamo se glasbeni video oziroma videoklip, to je vizualizacijo nekega glasbenega komada v obliki (kratkega) filma. Videoklipi so danes prisotni v vseh glasbenih zvrsteh. Tako predstavljajo n.pr. narodno-zabavni ansambli svoje viže pogosto pred planinskimi vršaci ali žuborečimi potoki. Tudi na področju klasike obstaja vrsta glasbenih ilustracij, pri čemer velja omeniti vsaj „Ricercar“ Johanna Sebastiana Bacha v režiji Helmuta Stadlmanna, „Kantrimiusik“ Mauricia Kagla, „Klavirski koncert“ Franka Martina režiserja Adriana Marthalerja, „Tretjo simfonijo“ Henrika Goreckega v režiji Tonyja Palmerja, posnetke z Nigelom Kennedyjem, Vaneso Mae in Anno Netrebko ali pa izdaje produkcijske hiše „Naxos“, ki je n.pr. Mozartovo „Praško simfonijo“ podložila s poetičnimi posnetki tamkajšnjih gradov. Posebno vlogo pa so odigrali videoklipi na področju pop glasbe in sicer tako na glasbo, modo in vedenjski slog v okvirju glasbenih subkultur kakor tudi na estetske kode in oblike televizijske prezentacije, filma in reklame (prim. Frith et al., 1993).

\section{Teoretične predpostavke in prvi praktični eksperimenti}

Ideja glasbene vizualizacije oziroma razmišljanje o odnosu med videnim in slišanim, med tonom in barvo, med glasbo in sliko, ima že dolgo in pestro zgodovino. Poleg mitoloških pričevanj se 
je ohranila vrsta zapisov iz stare Kitajske, Indije in Perzije, ki se ukvarjajo z odnosi med glasbenimi in barvnimi nizi. V grški antiki je razvil Aristoteles na številčni osnovi utemejen harmonski princip, ki je predvideval sedmerno delitev tonov, barv in okusov. V času renesanse se je med drugimi s tem problemom ukvarjal tudi Leonardo da Vinci. Nadalje velja omeniti Athanasiusa Kircherja, izumitelja laternae magice in avtorja večih del o optiki in akustiki, ter znanstveni spor med Isaacom Newtnom, izumiteljem barvno-glasbenega kolesa, in Wolfgangom Goethejem. Omenjena sta se strinjala v tem, da določene barve korespondirajo z določenimi toni. Nista pa se mogla zediniti o vprašanju, katere barve to so in pa tudi ne o metodi, s katero bi se dalo to hipotezo znanstveno dokazati (prim. Buchheim, 1991).

Prvi prenos teoretičnih predpostavk v glasbeno prakso je uspel jezuitskemu bratu in matematiku Bertrandu Castelu leta 1729. Castel je konstruiral svetlobni čembalo v skladu s svojim subjektivnim doživljanjem odnosa med barvo in tonom. Tehnika je bila več kot preprosta. Nad čembalom je bil montiran okvir z vrsto majhnih okenc z barvnimi stekli. Vsako okence je imelo zaveso, ki se je ob pritisku na določeno tipko odgrnila, tako da so se za hip pokazali prebliski gorečih sveč, ki so se nahajale za barvnimi stekli.

Pomemben mejnik je nadalje predstavljalo simfonično delo „Prometej” (Poema ognja) Aleksandra Skrjabina (1871 - 1915), v katerem je skladatelj skušal preko svetlečega klavirja pričarati vizualno predstavo ognja. Skrjabin, ki imel določene sinestetične izkušnje, je svoj glasbeni lightshow koncipiral ž namenom, preko celostnega glasbenega doživetja dvigniti poslušalce na višjo, quasi religiozno stopnjo zavesti v skladu s svojimi (teozofskimi) filozofskimi predstavami. V te namene je poleg orkestralne komponiral se dodatno svetlobno partituro, na osnovi katere naj bi svetleči klavir glasbi ustrezno projiciral v koncertno dvorano barvne snopiče. Premiere svojega dela, ki je bilo prvič izvedeno leta 1915 v New Yorku, Skrjabin ni več doživel. Publika pa ni bila preveč navdušena, saj deloma ni razumela sistema, na osnovi katerega je Skrjabin gradil svoje asociacije med glasbo in lučjo. Tudi svetleči klavir je razočaral, saj je bil instrument kljub temu, da je že uporabljal električno energijo, prešibak, da bi spremenil dvorano v svetlobno morje (prim. Pütz, 1995).

Po vrsti več ali manj dorečenih poskusov, med drugim tudi s svetlečimi orglami, kot jih je na svojih koncertih uporabljal Alexander Laszlo ${ }^{2}$, so glasbene vizualizacije oziroma multimedialne prezentacije resnično zaživele šele v dvajsetih letih prejšnjega stoletja. Po eni strani so slonele na estetskem credu, ki se je zavzemal za prekoračevanje meja med različnimi umetniškimi zvrstmi in estetsko doživljanje preko vseh čutil, po drugi strani pa na tehnoloških moznostih - s tem je bil mišljen predvsem film -, ki so omogočale neposredno povezavo slike in tona s sinestetičnimi učinki.

Med predhodnike multimedialne umetnosti $\mathrm{v}$ danasnjem pomenu besede sta sodila Viking Eggeling und Walther Ruttman ${ }^{3}$ : Oba sta bila po izobrazbi slikarja. 1921 je bil prvič predstavljen Ruttmanov film „Opus 1“. Zanj je Ruttman naslikal na steklene plošče vrsto motivov oziroma grafičnih elementov in jih posnel na filmski trak. Glasbo pa je napisal Max Butting v skladu z grafičnimi predlogami. „Opus 1“ lahko zato smatramo kot prvi primer filmske glasbe, saj je bilo do tedaj v navadi, filmske prizore glasbeno ilustrirati z že znanimi komadi, medtem ko je možnost, videno uglasbiti, predstavljalo novost.

Med najpomembnejse ustvarjalce abstraktnega glasbenega filma sodi Oskar Fischinger (1900 - 1967). Vsestransko nadarjen Fischinger je študiral violino in gradnjo orgel ter tehnično risanje. Navdušen nad Ruttmanovim „Opus 1” se je najprej posvetil absolutnemu filmu, v katerem je povezoval svoje glasbene in grafične sposobnosti. Nato je ustvarjal risanke, po emigraciji iz fašis-

Madžarski komponist in pianist Laszlo je med drugim napisal tudi teoretično delo z naslovom "Color-Light-Music”.

Ruttman je bil tudi glasbenik in njegov najbolj znani film je naslovljen z „Berlin: Die Sinfonie einer Großstadt”. 
tične Nemčije v Ameriko pa tudi reklamne spote ter filmske animacije, med drugim tudi za Walta Disneya pri realizaciji njegovega filma „Fantasia“. Fischinger je znan predvsem po tem, da je svoje glasbene filme gradil na lastnih prestavah o direktnih analogijah med glasbenimi in barvnokoreografskimi oblikami. Pri tem je animiral grafične objekte sinhrono h glasbi, pri čemer je, kot n.pr. v svojih leta 1932 koncipiranih „Glasbenih ornamentih“, obravnaval ton kot sliki enakovredni element estetskega izraza. Med njegova nabolj znana dela sodi film „Komposition in Blau: Lichtkonzert Nr. 12" na glasbo Otta Nicoleija. Nadaljnji glasbeni filmi obsegajo dela popularne klasike od Bacha, Beethovna in Brahmsa preko Griega in Liszta do Verdija in Wagnerja (prim. Moritz 2004).

Pravo evforijo zanimanja za sinestetične fenomene ter njihove umetniške simulacije pa so sprožili „Barvno-glasbeni kongresi“, ki jih je v letih 1927, 1930, 1933, 1936 organiziral psiholog in glasbeni estetik Georg Anschütz. Anschütz, ki se je kasneje postavil v službo nacističnega aparata, je v tem času aktivno raziskoval problem sinestezije in je na te kongrese povabil poleg psihologov in drugih znanstvenikov tudi glasbenike, plesalce, slikarje in filmske ustvarjalce, aktivne na področju multimedialnih umetniških oblik. Sodelovala sta tudi Alexander Laszlo in Oskar Fischinger (prim. Jewanski, 2006).

\section{Vpliv glasbenega filma}

Nadaljnje vplive na razvoj videoklipa kot samostojne estetske oblike lahko iščemo v glasbenih filmih, predvsem tistih, ki so bili posvečeni različnim žanrom popularne glasbe. Pri tem velja spomniti na dejstvo, da obravnava že prvi celovečerni tonski film z naslovom „The Jazz Singer” (Warner Bros) iz leta 1927 zgodbo uboznega zidovskega pevca, ki mu je kljub mnogim preprekam uspelo postati slavljena broadwayska zvezda. Tesno povezani s tem filmskim žanrom so bili plesni filmi, pri čemer so navduševali predvsem Fred Astaire, Ginger Rogers und Eleanor Powell ter serija filmov z naslovom „Broadway Melody”, ki so v Evropi bistveno prispevali k popularizaciji jazza in swinga. Dramaturška koncepcija teh filmov je bila dokaj nezahtevna, saj je zgodba sama služila le kot rdeča nit, ki je povezovala plesne in glasbene točke, v glavnem uspešnice, ki so jih gledalci oziroma poslušalci poznali že iz drugih kontekstov (plesi, gramofonska plošča, radio). Obstajala pa je tudi še danes aktualna medsebojna odvisnost med tovrstnimi filmi, filmskimi posnetki (broadwayskih) muziklov oziroma odrsko postavitvijo glasbenih filmov, kot je n.pr. muzikal „Dirty Dancing”.

Podobno koncipirani so bili revijski filmi kot so jih med tridesetimi in petdesetimi leti snemali na nemško govorečem področju. Tudi ti filmi so se opirali na odrske žanre (muzikal, opereta) in so bili prežeti s številnimi plesnimi in pevskimi točkami. Njihovi lahkotni sižeji so v glavnem tematizirali romantično-dramatične zaplete pri inscenaciji neke revije z obveznim srečnim koncem. V času nacistične Nemčije je med zvezde tega žanra sodila dinamična Marika Rökk.

Priljubljene pa so bile že od začetka tonskega filma tudi biografske zgodbe klasičnih glasbenikov, posebno komponistov. Po eni strani je dejstvo, da so bili protagonisti - vsaj po imenu - znani tudi širokim množicam, zagotavljalo uspeh filma. Po drugi strani pa je po tej poti našla njihova glasba poslušalce tudi izven ozkega kroga običajne koncertne publike: med najlepše primere sodi film „Amadeus“ režiserja Miloša Formana, ki je navdušil celo mladostnike iz nekdanje punkovske scene. Tudi uporaba znanih melodij (n.pr. Mahlerjeva 5. simfonija v Viscontijevem filmu „Smrt v Benetkah") je bistveno prispevala h popularizaciji klasične glasbe, tako da so bile mnoge skladbe kasneje izdane na ploščah z opombo, da gre za 'soundtrack' nekega določenega filma. Sem sodi tudi glasba za Kubrikov film „Odiseja 2001“, ki vključuje med drugim dele skladb „Atmosfere“, 
„Requiem“ in „Lux Eterna“ Györgyja Ligetija, odlomke iz „Govoril je Zaratustra“ Richarda Straußa ter nepozabni prizor poplesovanja vesoljnih ladij na valček „Na lepi modri Donavi“ Johanna Straußa ${ }^{4}$.

Tem močnejši so bili sinergetski efekti med popularnostjo glasbenih filmov, prodajo nosilcev tona in nastankom mladostniških subkultur na področju rock in pop glasbe. Komad „Rock Around the Clock“ (Bill Haley) je preko filma „Blackboard Jungle“ iz leta 1955 postal himna revolte v znamenju mladostništva. Sledile so komercialne uspešnice z Elvisom Presleyem, Conny Froboes und Petrom Krausom. Poleg posnetkov znamenitih festivalov (Woodstock) je predvsem film „Easy Rider“ propagiral izstopništvo in življenski slog onkraj strogih družbenih norm. „Saturday Night Fever“ z Johnom Travolto je s svojimi vratolomnimi plesnimi scenami povzročil pravo disko mrzlico, film „Sid in Nancy“ je razširjal morbidno punkovsko vzdušje etc. V kakšnih oblikah se je odvijal sinergetski marketing, je razvidno med drugim iz podatka, da je posnetke naslovnih komadov filma pogosto financirala sodelujoča industrija nosilcev tona.

\section{Soundies in scopitone}

Pot do videoklipa kot samostoje vizualizacije nekega glasbenega komada pa ni vodila samo preko glasbenega filma, ampak tudi preko nekaterih drugih, v glavnem v pozabo odrinjenih predhodnikov. že v osemdesetih letih devetnajstega stoletja so namreč poznali neke vrste ilustrirane pesmi, saj je bilo možno n.pr. s pomočjo aparata imenovanega vitafon vzporedno z glasbo kazati tudi slike s fotografskih plošč. Omeniti velja nadalje „Phono-Ciné-Théâtre“, ki so ga leta 1900 prvič predstavili v Parizu in ki je veljal za eno največjih atrakcij takratne svetovne razstaves.

Desetletja kasneje so vzbudili v ZDA nekaj pozornosti t.i. soundies, čno-beli triminutni glasbeni filmi, v katerih so nastopali najpomembnejši predstavniki takratnega jazza. Predvajali so jih preko vizualnih juke-boxov (panoram) z ekranom, na katerega so vzvratno projicirali 16 milimetrske filme. Prvi soundies, ki jih je bilo moč občudovati predvsem v nočnih klubih, so se pojavili 1939 in so se obdržali na trgu do vstopa Združenih držav Amerike v drugo svetovno vojno. Po vojni pa ni bilo več zanimanja za to glasbeno-vizualno zvrst.

Podobno konstruiran je bil scopitone oziroma cinebox, prav tako neke vrste križanec med juke-boxom in filmsko projekcijo. Njegova tehnologija se navezuje na odpadni material iz druge svetovne vojne, in sicer na snemalne aparate, kakor jih je v vohunske namene uporabljalo francosko letalstvo: šlo je za posebno adaptacijo $16 \mathrm{~mm}$ kamere v projekcijske namene. Pojem scopitone se zatorej ne nanaša na kratke filme, ki jih je bilo moč predvajati na teh aparatih, ampak na aparate same, ki so delovali kot običajne glasbene skrinjice: Poslušalci/gledalci so za kovanec določene vrednosti aktivirali mehanizem in izbrali iz ponudbe tisti glasbeni film, ki so ga želeli videti oziroma slišati.

Vizualizacija takrat popularnih popevk z interpreti kot so bili Johnny Hallyday, Paul Anka, Petula Clark in Sylvie Vartan ni imela večjih estetskih zahtev. Posamezne pesmi so bile v glavnem posnete pred naravno kuliso in so se odlikovale s kičasto inscenacijo teksta. Kamera je bila statična. Za dinamiko pa so poskrbeli obvezni plesni vložki, pogosto z nespregljedljivo erotično komponento, kot so bile n.pr. deklice v bikinih oziroma prizori, ki so namigovali na poltenost. Režiserka in producentka teh kratkih filmov je bila Daidy Davis-Boyer, znana pod imenom 'Mamy Scopitone', ki je posnela nekaj sto tovrstnih komadov.

V Franciji in nekaterih drugih evropski državah je med leti 1962 in 1965 skopitone užival izjemno popularnost. Američani pa se niso mogli ogreti ne za to tehnično novost ne za evropske

David Bowie je napisal pod vplivom tega filma enega svojih najbolj znanih komadov z naslovom "Space Oddity".

prim. 
zvezdice, ki so bile na njihovem trgu popolne neznanke. Obstajale pa so tudi estetske prepreke, saj je bila ameriškemu okusu tuja tako zadržana erotika kakor tudi mnoge aluzije na tipične scene in vsebinske pomene in ne nazadnje - kot n.pr. v primeru Sylvie Vartan - francoski jezik. Tako je bilo posnetih v tej deželi le malo glasbenih točk za scopitone, ki so pa bile veliko bolj dinamične od francoskih in so se pogosto nahajale na meji pornografije ${ }^{6}$ : sem sodi predvsem vrsta filmov, ki so jih posneli s pomanjkljivo oblečenimi plesalkami pariskega varijeteja Crazy Horse. Aparat sam pa so kasneje uporabljali $\mathrm{v}$ informacijske in izobraževalne namene $\mathrm{v}$ muzejih in podobnih javnih institucijah.

\section{Expanded cinema in psihedelična umetnost}

V šestdesetih letih so na estetiko kasnejših videoklipov vplivale tudi trendi s področja mixed media, ki so povezovali svetlobne umetnine, kinetske slike in fotografske projekcije z drugimi umetniškimi zvrstmi in ki so se pogosto nahajali na stičišču avantgardne umetnosti in rock kulture. Pri tem je igralo posebno vlogo sicer kratko, toda za način, kako danes proizvajamo, uporabljamo in ne nazadnje tudi razumemo pop glasbo, odločilno srečanje med pop art umetnikom Andyjem Warholjem in skupino „The Velvet Underground“. Warhol je imel vrsto stičnih točk s pop glasbo. Bil je intimen prijatelj Biance in Micka Jaggerja, katerega portret sodi med njegova najboljša dela. 1971 je naredil osnutek za ovojnico plošče „Sticky Fingers“ skupine Rolling Stones ter ustvaril njihov logo, rdeča usta z iztegnjenim jezikom. Nadalje je s svojim spremstvom pogosto zahajal v diskoteke, kjer je - oborožen s fotografskim aparatom in magnetofonom - dokumentiral ta del ameriškega vsakdanjika. In ker si je tudi sam želel postati rock zvezda, je 1965 sestavil rock skupino, v kateri so igrali še drugi znani predstavniki pop arta, med njimi Jasper Johns, La Monte Young, Walter de Maria in Claes Oldenburg.

Pomembnejši tako za estetiko rock koncertov in multimedialnost klubskega doživetja kakor tudi za oblikovanje videoklipov pa so bili njegovi projekti s področja 'razširjenega filma' (expanded cinema), ki so se konceptualno navezovali na filmske eksperimente nekdanjega Bauhausa. Konkretno je šlo za sočasne projekcije na statična ali gibajoča se platna, light-shows ter vključevanje plesa, gledališke umetnosti ter glasbe. Podobno kot pop art se je razumela tudi ta estetska zvrst, ki se je teoretično opirala na Marschalla McLuhana in njegovo teorijo o 'globalni vasi', kot odslikavanje tehnološko in medijsko obeležene resničnosti ter kompleksnosti modernega urbanega življenja.

Posebno vlogo so pri tem odigrali multimedialni spektakli z rock glasbo v new yorški diskoteki „The dom“. Igrali so „The Velvet Underground“, na moč glasno (in deloma tudi razglašeno), pred skupino pa so plesali gogo girls in gogo boys. Na platno v ozadju odra oziroma kasneje tudi na stene prizoriščnega prostora so projicirali warholjeve filme, prekinjene s stroboskopskimi bliski in iskajočimi žarometi. Tako so bili poslušalci oziroma gledalci od vseh strani vpeti v dogajanje. Tudi nevidna prepreka med izvajalci in publiko je padla, saj v dvorani ni bilo ne miz ne sedežev, in kdor je hotel, je lahko prišel na oder, se aktivno vključil v dogajanje ali pa se prepustil plesu.

V tej atmosferi kreativne anarhije je izpadel vsak večer drugače. Toda nekaj so imele te prireditve le skupnega. „Prej se je bilo možno ob poslušanju prepustiti glasbi in asociirati“, sta zapisala Bockris in Malanga, ožja Warholjeva sodelavca. „Tukaj pa je bila ustvarjena plastična podoba tega, kar je želela glasba povedati in nič ni bilo več prepuščeno fantaziji“. In ker je postala vizualna komponenta neločljiv del glasbenega doživetja, sta omenjena videla v tem nadaljevanje Warholjevega dela kot portretist in primerjala te Exploding Plastic Inevitable poimenovane spektakle večdi- 
menzionalnemu portretu iz mesa in kosti. „Filmi so bili portreti oseb na odru. Ljudje na odru so bili svoj lastni portret. Pesmi, ki so jih igrali Velveti, so bili portreti ljudi, ki so jih poznali, in publika, ki je bila filmana, fotografirana in opevana $\mathrm{v}$ pesmih, je bila prav tako portretirana in je $\mathrm{s}$ tem postala tudi sama neločljiv del tabloja z imenom Exploding Plastic Inevitable“ (cit. po Barber-Keršovan, 1997, s. 156).

Na zahodni obali Združenih držav je prišlo do nekoliko drugačnega združevanja akustičnega in vizualnega. Le-to je bilo neposredno povezano s psihedeličnim gibanjem, ki se je prizadevalo za doseganje stanja razširjene zavesti kot višje oblike spoznanja in hkrati tudi kot ekstatične revolte proti racionalno organizirani ameriški družbi. Glasbeni eksperimenti s tega področja so se pogosto navezovali na izkušnje s psihedeličnimi mamili, predvsem z LSD-jem, saj se pod vlivom te substance radikalno spremeni percepcija. Slušno doživetje se intenzivira in stimulira imaginacijo, kar pogosto rezultira $\mathrm{v}$ hacilunacijskih vizualnih predstavah.

Estetske reinterpretacije psihedeličnega izkustva so zatorej vsebovale poleg glasbenih tudi optične komponente. Koncipirane so bile z namenom, preko mešanja različnih tehnik in umetniških zvrsti ustvariti irealne situacije, ki so silile gledalca/poslušalca k celostnem doživetju, kot n.pr. pri ‘totalnem gledališču' Franka Zappe in njegovih „Mothers of Invention”. Legenda pa so postali tudi burni „Acid tests” Kena Keseya, avtorja romana „Let čez kukavičje gnezdo”, ki jih lahko smatramo kot predhodnike velikih rock festivalov. Podobno kot pri warholjevih expanded cinema projektih je šlo tudi pri teh akustično-vizualnih ceremonijah v znamenju iskanja lastne osebnosti za neke vrste happening z glasbo, plesom, filmom in svetlobnimi učinki (prim. Barber-Keršovan, 1990).

Toda psihedelična glasba ni bila namenjena samo stimulaciji 'notranjega filma', ampak je predstavljala tudi integralni del celostno usmerjenih estetskih projektov. Tako je bila skupina ,Jefferson Airplane" del umetniške kooperative, ki se je poleg glasbe ukvarjala z oblikovanjem plakatov in ovitkov plošč ter s svetlobno umetnostjo. Neke vrste veliko družino so nadalje predstavljali „The Greatful Dead", katerim so med drugim pripadali designer Rick Griffin in lirik Robert Hunter. Poleg tega so bili mnogi glasbeniki hkrati upodobljajoči umetniki, kot n.pr. David Getz, bobnar skupine „Big Brother and the Holding Company” in Michael Ferguson od skupine „The Charlatans”, ki sta etablirala psihedelični plakat kot samostojno grafično zvrst.

\section{MTV - Music Television}

Čeprav so že razgibani filmi „A Hard Days Night“ in „Strawberry Fields Forever“ skupine „The Beatles“ s svojimi ritmičnimi rezi anticipirali kasnejše videoklipe, velja kot prvi primer tega žanra „Bohemian Rhapsody“ angleške skupine „Queen“, ki se je 1975 prva poslužila video tehnike za snemanje kratkega promocijskega filma, namenjenega predvajanju na televiziji. Prav tako kot predstavniki video arta so se tudi prvi režiserji videoklipov pogosto sklicevali na avantgardni oziroma absolutni film dvajsetih let (prim. Uka, 1994, s. 350). Na te vzornike so se navezovali tudi „Queen“, ki so v klip „Radio Gaga“ montirali scene iz filma „Metropolis“ Fritza Langa. Reminiscence na isti film je kasneje uporabila Madonna v enem njenih najuspesnejših klipov, „Express Yourself".

Promocija glasbe preko televizije je predstavljala novost, saj le-ta - v razliko od radija - dolgo časa ni veljala kot izrazito glasbeni medij. Sicer je bilo tudi v televizijskih programih vedno veliko glasbe, ne le v filmih in televizijskih serijah, ampak tudi v obliki akustičnih tapet v drugih formatih, glasbenih showih, reklamnih spotih etc. Oddaje, posvečene samo glasbi, pa so bile v 60. in 70. letih zelo redke, posebno tiste, namenjene rocku in popu: Med najpomembnejše so sodile „Top of the Pops” v Angliji, „American Bandstand” v ZDA in „Beat Club“ v ZRN. Ta situaci- 
ja se je dramatično spremenila z uvedbo kabelske televizije ter nastajanjem privatnih televizijskih postaj, ki so rabile nove programske vsebine, tako da so čas oddajanja pogosto zapolnjevali z večurnimi programskimi bloki, namenjenimi popularni glasbi.

V začetku osemdesetih letih so pomembni impulzi prihajali tudi s strani glasbene industrije, ki se je - podobno kot filmska industrija - zaradi novo nastalih ponudb na področju preživljanja prostega časa in ne nazadnje tudi zaradi množične razširjenosti televizije nahajala v recesiji. Izhod iz krize je obljubljala MTV (Music Television), ki so jo s financno podporo velikih gramofonskih hiš ustanovili 1981 v New Yorku. Ta privatni, na rock in pop glasbo specializiran televizijski kanal je bil osnovan na komercialni osnovi in je bil namenjen glasbenemu marketingu v velikem slogu in z velikim geografskim dometom. Po svoji razširjenosti je namreč MTV mednarodna televizijska postaja, ki jo danes lahko sprejemajo - v regionalno obarvanih različicah - v več kot osemdesetih deželah. Največja regionalna oddajnika sta „MTV USA“ in 1987 ustanovljena „MTV Europe“. Njej pripada 27 evropskih dežel ter Izrael, gledajo pa jo lahko tudi v Rusiji in drugih državah nekdanje Sovjetske zveze.

Ob svojem nastanku je MTV predstavljala inovativen medijski produkt, koncipiran po preciznih finančnih, tehničnih in estetskih kriterijih. Edino programsko vsebino je predstavljala reklama: reklama za nosilce tona v obliki videoklipov ter reklama za določene konzumne dobrine, saj se je - v razliko od tradicionalnih, družinsko usmerjenih televizijskih his - MTV specializirala na zelo ozek segment publike, namreč na mlade potrošnike med 14 in 29 letom. Kot samozvani 'ambasador mladih' je MTV zasledovala vizijo o t.i. 'global MTV-nation', transnacionalni družbi prostega časa in hedonizma, ki naj bi ji pripadali mladostniki iz vsega sveta, neodvisno od njihovega socialnega, religioznega ali kulturnega porekla. Pomembno vlogo so pri tem igrali VJs (video jockeys), ki so vodili oddaje in skušali vzpostaviti povezavo med programom in publiko. S svojo starostjo, imidžem, žargonom, mimiko in gestiko so uteleševali tako glasbeno zvrst, ki so jo predstavljali, kakor tudi socialni univerzum pripadajoče glasbene subkulture.

Finančno se je računica sprva izšla. Popularizacija glasbe preko televizije z globalnim dometom je bila veliko cenejša tako od promocije preko regionalno organiziranih radijskih postaj in kakor tudi od običajnih turnej, tako da je glasbena industrija preko svojih specializiranih oddelkov (Polygram Video, Warner Home Video) z veseljem prevzela produkcijske stroške in brezplačno zalagala glasbeni kanal z videoklipi in glasbenimi informacijami. Nadaljni vir dohodka so bili sponzorji kot Benetton, Swatch, Levi Strauss, Wrangler, Nike, Puma in Pepsi Cola, torej proizvajalci produktov, ki jih je bilo moč povezovati z glasbo, modo in mladostništvom.

Manj uspešna je bila MTV pri doseganju drugih ciljev. Postala je sicer centralni informacijski organ za popularno-glasbene zadeve in je s svojo filozofijo globalne vasi nedvomno veliko prispevala tudi k temu, da so si glasbene kulture postale bližje. Ni ji pa uspelo ustvariti zaželjeno 'MTV-nation', saj naletijo globalni komunikacijski sistemi na lokalno pogojene politične, ekonomske, socialne in kulturne predpostavke in te niso bile povsod dovzetne za programe, ki so dajali prednost angloameriškim izvajalcem in komadom $v$ angleškem jeziku. Upoštevajoč ta dejstva, je MTV uvedla regionalne oddajnike $\mathrm{z}$ različnimi vsebinskimi poudarki. Toda kljub temu je celo v zahodno orientirani Japonski, ki se sicer ponaša z živahno glasbeno sceno, ta televizijski kanal skoraj spodletel.

\section{Videoklip kot postmoderni tekst}

Videoklipi so sicer primarno namenjeni prodaji nekega določenega glasbenega komada ${ }^{7}$, in tako se ima vrsta glasbenikov in skupin, predvsem „Duran, Duran“, Bon Jovi, Michael Jackson

V tem smislu bi lahko kot prvi videoklip smatrali „Film Disque 957”, ki ga je 1928 posnela Germaine Dula v svrho promocije plošče s Chopinovim Preludijem st. 6. 
in Madonna zahvaliti za svoj uspeh širokopotezni promociji preko MTV. Kritika pri tem omenja predvsem dejstvo, da je MTV favorizirala glasbenike z ustrezno optiko in s tem med drugim sprožila tudi nastanek t.i. 'designer-bands', kot n.pr. „Milli Vanilli“, pri katerih so protagonisti na odru fizično ustrezali estetskim normam potrosniške družbe, medtem kot so glasbo samo izvajali nevidni profesionalci.

Kljub temu pa videoklipov ne smemo ocenjevati samo po njihovi komercialni vrednosti, saj obstajajo med posameznimi glasbenimi ilustracijami ogromne kvalitativne razlike. Tako najdemo poleg okornih, stereotipnih posnetkov glasbenikov in skupin 'v akciji', pogosto prepletenih z dinamičnimi plesnimi scenami, tudi drzne multimedialne eksperimente, ki s svojo fantazijo, precizno sinhronizacijo in komplicirano računalniško animacijo predstavljajo prave majhne celostne umetnine. Pri tem velja omeniti predvsem avantgardistične skupine britanske alternativne scene („Cabaret Voltaire“, „Psychic Television“, „Test Department“, „Factory Records Icon“), ki so v začetku osemdesetih let ustvarjale klipe z neobičajnimi vsebinami in ki so svoja kritična sporočila namenjale sicer ne množični, zato pa tem bolj zahtevni publiki. Temu primerno so jih tudi predvajali predvsem $v$ galerijah in podobnih kulturnih institucijah.

Toda tudi na MTV je bilo možno najti prave majhne glasbene dragulje. Predvsem David Bowie, ki se je rad skliceval na pop art warholjeve „Factory“, skupina „Pet Shop Boys“ ter Michael Jackson in Madonna so razumeli videoklip kot samostojen medij estetskega oblikovanja z bolj ali manj izrazitimi umetniškimi ambicijami. Poleg mladih filmarjev so se zato pri produkciji klipov udeleževali tudi nekateri renomirani filmski ustvarjalci, med njimi Ken Russel in Federico Fellini, ki so si prizadevali po tej poti nagovoriti široko publiko. Visokim estetskim predstavam primerno so se deloma povišali tudi producijski stroški, tako da je n.pr. Jacksnov „Thriller“ v režiji Johna Landisa, eden najuspešnejših klipov vseh časov, stal kar 3.000.000 nekdanjih nemških mark.

Ne le v odnosu na kvaliteto, tudi vsebinsko se videoklipov ne da brez nadaljnjega spraviti na skupni imenovalec. Holger Springklees je predlagal naslednjo klasifikacijo:

1. Performativni klip, ki neposredno odslikava dogajanje na odru („Life is Live“ graske skupine „Opus")

2. Narativni klip, ki se sestoji iz slikovnega niza in ga gledalci lahko dekodirajo kot zgodbo ali pa vsaj kot odlomke neke zgodbe („Lucky in Love“ Micka Jaggerja)

3. Semi-narativni klip, v katerem se upodobitev glasbenikov meša z odlomki zgodbe

4. umetniski klip, ki ne tematizira niti glasbenikov niti zgodbe, ampak predstavlja samostojno audio-vizualno kreacijo. Optična komponenta pri tem pogosto sloni na računalniski animaciji („Sledgehammer“ Petra Gabriela; cit. po Uka, 1994, s. 349) ${ }^{8}$.

Springkleesova klasifikacija zveni sicer logično. Kljub temu pa ostaja ta pregled veliko pregrob, saj se mnoge glasbene ilustracije ne dajo strpati v omenjene okvirje. Ustvarjalci videoklipov namreč ne upoštevajo samo vseh estetskih oblik (glasba, jezik, ples, gledališče, film, računalniška grafika; prim. Lampalzer, 1992, s. 14) v najrazličnejših kombinacijah, ampak tudi brezobzirno ropajo v bogati zakladnici kulturne zgodovine in se za svoje reinterpretacije poslužujejo vsega, kar jim pride pod prste. Njihove akustično-vizualne lepljenke se poslužujejo estetskih postopkov kot so plagiat, parodija in rekontekstualiziacija in predstavljajo del postmoderne kulture v smislu 'anything goes', v kateri se avantgardistične tendence zlivajo z elementi popularne kulture in reklame v neločljivo celoto.

Več skupnih potez kot vsebinska sporočilnost videoklipov kažejo formalno-dramaturški posegi. Sem sodijo fragmentacija in segmentacija informacijskih vsebin, pogosti stilistični preskoki, zlivanje realnosti in virtualnosti, kolaps preteklosti in prihodnjosti v imaginarno sedanjost, obože-

Področje klasične glasbe je v veliki meri prevzelo marketinške strategije popularne kulture. Tudi mnogi klasični klipi se zgledujejo po popularnih vzornikih. Temu primerno se tudi klasifikacija klasičnih klipov v principu ne razlikuje od omenjene kategorizacije (prim. h temu Behne, 1994, s. 10). 
vanje hedonizma ter prevladovanje vizualnih nad verbalnimi in - paradoksno kot je to slišati v odnosu na glasbeno televizijo - tudi glasbenimi elementi. Nadaljnje značilnosti so hitri rezi, sinhronizirani z glasbo, pogoste menjave pozicije kamere, igra z različnimi časovnimi odnosi in menjava barvnih in črno-belih sekvenc, ki tem pustolovskim izletom v surealne svetove doživljanja dajejo vtis hitrosti, mobilnosti in gibanja.

\section{MTV kot postmoderni tekst}

Podobne lastnosti so odlikovale tudi zgodnjo MTV kot medij. Sicer je - tako kot drugi televizijski kanali - tudi prvotna MTV oddajala po določeni programski shemi z lestvicami uspešnic, oddajami po željah poslušalcev in t.i. rockumentaries kot hibridno obliko, ki je povezovala zabavno oddajo z dokumentacijo. Nadaljnje programske točke so bile reklamni spoti ter infotainment, to so kratke informacije o vsem, kar se tiče rock in pop glasbe. Toda kar se tiče nizanja videoklipov in drugih vsebinskih enot so bile te estetsko tako tesno med seboj povezane, da ni prišlo do večjih stilnih prelomov, ampak so se posamezni deli zlili v neprekinjeni glasbeno-vizualni tok. Tako kot videoklipi na mikro ravni je zato tudi MTV na makro ravni funkcionirala kot postmoderni tekst, v katerem se vsebina podreja obliki in se medij spremeni v sporočilo v smislu Marshalla McLuhana.

Kakšen pomen so v prvih letih oddajanja pripisovali tej estetski dimenziji, priča med drugim tudi dejstvo, da se je vrsta sodelavcev ukvarjala samo z izborom in umeščanjem reklamnih spotov v svrho poenotenja s predhodnimi oziroma sledečimi glasbenimi točkami. Še več: reklame, ki niso ustrezale določenim kriterijem, niso bile upoštevane, tako da so bili mnogi sponzorji prisiljeni prilagoditi svoje spote estetiki glasbene televizije. Zelo pomembno vlogo je igrala pri tem tudi umetelna transformacija lastnega loga, ki je simbolizirala stalno spremembo glasbenih in drugih mod.

S tovrstnimi pristopi je MTV etablirala novo gramatiko televizijskega jezika in spremenila tako način gledanja televizije kakor tudi konzumiranja glasbe, saj je večina gledalcev/poslušalcev kljub močnemu povdarku na optičnih elementih sprejemala njen program kot neke vrste vizualni radio oziroma multimedialno tapeto $\mathrm{v}$ smislu nevsiljive spremljevalke drugih aktivnosti. Nadalje so eksperimenti glasbene televizije pomembno vplivali na estetsko oblikovanje drugih televizijski postaj - lep primer je nemško-francoski kulturni kanal „Arte“ -, ki so prevzele od MTV nekatere tipične stilne prijeme.

\section{Videoklip je mrtev - živela vizualna glasba}

Sredi osemdesetih let se je čar vključevanja glasbenih klipov v neskončni tok dogajanja, ki so ga v času pionirskih poskusov MTV-ja pretrgovali samo prav tako umetelno izdelani reklamni spoti, obrabil. Tudi sinestetični učinki so zbledeli, tako da je ne nazadnje tudi videoklip kot izrazna oblika pričenjal izgubljati svojo prvotno privlačnost. Število poslušalcev/gledalcev se je dramatično zmanjšalo in temu primerno tudi število sponzorjev. Tako je morala MTV revidirati svoj prvotni koncept ter upoštevati tudi druge programske vsebine (risanke, reality in comedy shows, televizijske serije) in se je s tem vse bolj približevala konvencijam etabliranega televizijskega dela.

Videoklip sam je v začetku devetdesetih let sicer doživel še neke vrste renesanso, predvsem z uvedbo novih glasbenih kanalov, kot je bila leta 1993 ustanovljena Viva, ki je oddajala v nemščini in ki je velik del programa posvetila domači produkciji. Paralelno so nastali tudi novi oziroma dodatni in nekaj starejši publiki namenjenimi programi VH1 in Viva Plus.

V novem tisočletju je zanimanje za videoklip ponovno upadlo. Med vzroke lahko prištevamo tudi že dalj časa trajajočo krizo glasbene industrije, ki si ne more več privoščiti dragih investicij 
v glasbene ilustracije: Posneto je manj videoklipov in še ti so v primerjavi z osemdesetimi leti pogosto slabše kvalitete. To pa seveda ne pomeni, da je hkrati upadlo tudi zanimanje za povezavo med sliko in glasbo. Ravno nasprotno: zanimanje se je povečalo, spremenile pa so se do tedaj običajne oblike produkcije, reprodukcije in distribucije.

Z množično uvedbo digitalne tehnike je ne le postalo možno, posamezne estetske elemente poljubno povezovati, jih preoblikovati oziroma ustvarjati tudi k glasbi v živo gibajoče se slike, ki se generirajo v smislu 'real time processing': Glasba je postala tudi integralni del novih oblik tehnologije zabave, kot so n.pr. računalniške igre. Tako je nastal virtualni svet multimedialnosti, v katerem ni več estetskih otokov posameznih umetniških zvrsti, ampak le tekoči prehodi med njimi: konvergenca čutil je našla nove izrazne možnosti v konvergenci medijev in interaktivnosti različnih kreativnih pristopov.

Vzporedno s tem se pojavlja nova estetika, ki povratno vpliva na optiko koncertov in drugih dogodkov v živo. Lep primer za to je t.i. VJ-ing, to je uporaba vizualnih učinkov, kot so jih razvili $\mathrm{v}$ diskotekah in na koncertih pop glasbe. Podobno kot DJ (disc jockey) je tudi VJ (video jockey), katerega prvotna naloga je bila predstavljanje videoklipov na glasbeni televiziji, neke vrste improvizacijski umetnik, ki v skladu z določeno glasbo ustvarja t.i. visuals kot nepogrešljiv del celostnega doživetja plesnega prostora. Pri tem upravlja s kompliciranim svetlobnim parkom in uporablja podobne estetske postopke kot DJ (sampling, looping). Sekvence uporabljenih visuals so pogosto vzete iz videoklipov, filmov in drugih grafičnih predlog in dobesedno citirane ali ustrezno preoblikovane prenesene v nove glasbeno-vizualne kontekste. Nadaljnji material predstavljajo lastni filmski posnetki oziroma grafične predloge in animacije.

S projekti, ki zahtevajo od poslušalca/gledalca večjo pozornost, kot jo posvečajo optični dimenziji v klubih ali na koncertih, se seli VJing po eni strani v muzeje in galerije, kjer se multimedialna scena popularne kulture prekriva z multimedialno umetniško sceno. Po drugi strani pa se vedno bolj širi digitalna video zgoščenka, namenjena predvsem individualni uporabi v domačem okolju. Na to tehnologijo se trenutno opira glasbena industrija v upanju, da bo lahko po tej poti kompenzirala že desetletje dolg upad zanimanja za konvencionalne nosilce tona. Obstajajo pa tudi drugi tehnoloski producenti, kot n.pr. proizvajalci mobilnih telefonov, ki aktivno prispevajo k vedno večjemu povpraševanju po vizualni glasbi.

Nadalje je VJing našel svojo pot v klasično glasbo. Leta 2006 je bila na programu tradicionalnega festivala v Bonnu, posvečenega Ludwigu van Beethovnu, med drugim tudi vrsta prireditev $\mathrm{z}$ naslovom „Roll_over_Beethoven. ClassicClips und VJing. Zur Synthese visueller Gestaltung und klassischer Musik". Tehnični in tudi estetski pristopi, s katerimi so operirali prisotni umetniki, so bili seveda različni in so se gibali od animiranega filma preko digitalnih slikovnih kompozicij do laserskih projekcij na hišne fasade. Skupna pa jim je bila želja po čim ožji sintezi med vizualnim designom in Beethovnovo glasbo?.

Nastali pa so tudi novi distribucijski kanali, predvsem preko interneta. „tunespoon.tv“ kaže videoklipe vseh žanrov v neprekinjenem video toku. Tudi MTV in nemški VH1 sta svojo ponudbo deloma preložila v internet. Nadalje velja omeniti se „YouTube“ in online video portal „MyVideo“, ki združuje največjo video skupnost v Zvezni republiki Nemčiji in ki omogoča ne le brezplačno ogledovanje (in download) neskončnega števila znanih klipov, ampak prestavlja tudi platformo za lastno oblikovanje glasbenih vizualizacij. Audio-vizualna ustvarjalnost, kakor jo je uvedla video kamera, je tako v spirali demokratizacije estetskega oblikovanja dosegla nov zavoj, saj je sedaj mogoče lastne izdelke deliti z istomislečimi po celem svetu. V internetu se zatorej ne rojevajo samo zvezde prihodnosti, ampak tudi nove estetske konvencije ter z njimi povezane nove oblike glasbene komunikacije in socialnih odnosov. 


\section{Summary}

The term video clip stands for the visualisation of a musical piece or song in the form of a short film. It is derived from the word 'video' (I see) as applied in the second half of the twentieth century to a certain method of recording and reproduction of visual and acoustic material.

The assumption that there is a strong correlation between the tone and the colour respectively the music and the picture has a long history. We find numerous evidences in ancient myths, in documents from old China, India and Persia, in the texts by Aristotle and Leonardo da Vinci, in the work on optics and acoustics by Athanasius Kircher, in the dispute between Isaac Newton and Wolfgang Goethe on the correspondence of tones and colours as well as in psychological studies on synaesthesia and multimodal perception.

The practice of musical visualisations however, always depended on the technology available. This article considers the following examples: experiments with the light cembalo by Bertrand Castel (1729), the colour organ as designed for the performance of Scriabin's Prometheus (1915), the abstract films by Oskar Fischinger (1900-1967), film music in general and music respectively dance films in particular, video art (Nam June Paik), the expanded cinema (Andy Warhol and The Velvet Underground) and the psychedelic art (Ken Kesey's Acid Tests and the groups Jefferson Airplane and The Grateful Dead).

The immediate forerunners of video clips were American soundies and the French visualized songs for an apparatus called scopitone. As the first video clip in the current sense the title „Bohemian Rhapsody" by the British group The Queen (1975) is considered: it used the video recording technique and was designed as a promotional film to be broadcast on television.

Since at that time music emissions on television were rare, in 1981 MTV was established, a commercial television channel that specialized in the worldwide marketing of popular music. Initially MTV was an innovative media product, planed according to precise financial, technical and aesthetic criteria. Its goal group were youngsters and its only content was video clips and advertising. As a self appointed 'ambassador of youth' MTV followed the vision of creating a 'global MTV nation', a transnational society of leisure and hedonism.

Though most musical illustrations have been shot for commercial purposes, there are also some clips of high artistic quality, especially by David Bowie, Madonna, Pet Shop Boys and Michael Jackson. Their post modern patchworks combine different art forms (music, language, dance, acting, graphic) and apply aesthetic procedures such as recontextualisation, reinterpretation and parody. Further characteristics are the fragmentation and segmentation of visual information, brisk rhythmical cuts and the frequent change of the camera position which give the impression of speed, mobility and motion. The same technique was also applied in the early days of MTV, resulting in an endless stream of audio-visual stimulation.

In the new millennium video clip as an aesthetic form as well as MTV as a medium began to loose its attraction. Not so however - especially due to digital technology - the visualizing of music itself. With new technological means a new world of multimedia emerged, in which there are no islands of sole artistic forms, but only fluid transitions between them, so that the convergence of senses became new expression possibilities in the convergence of the media. And last but not least, with YouTube and other internet based platforms new distribution channels have been opened, promoting new forms of musical communication and audio-visual creativity.

\section{Bibliografija}

Barber-Keršovan, Alenka (1990): „Turn on, tune in, drop out: Rockmusik zwischen Drogen und Kreativität“. V: Rösing, Helmut (izd.): Musik als Droge? Mainz. Parlando, Nr. 1. 
Barber-Keršovan, Alenka (1997): ,'Pop goes Art' -'Art into Pop'. Andy Warhol, The Velvet Underground und die Folgen". V: Kreutziger-Herr, Annette \& Strack, Manfred (izd.): Aus der neuen Welt. Streifzüge durch die amerikanische Musik des 20. Jahrhunderts. Hamburg: Lit.

Behne, Klaus-Ernst (1994): Bilder-Folgen. Auswirkungen unterschiedlicher Konzeptionen der Visualisierung von klassischer Musik im Fernsehen. Hannover: Hochschule für Musik und Theater.

Behne, Klaus-Ernst \& Kleinen, Günter \& de la Motte-Haber, Helga (izd.) (2006): Musikpsychologie. Inter-und multimodale Wahrnehmung. Göttingen et al.: Hogrefe.

Bódy, Veruschka \& Weibel, Peter (izd.) (1987): Clip, Klapp, Bum. Von der visuellen Musik zum Musikvideo. Köln: DuMont-Buchverlag.

Buchheim, Wolfgang (1991): Der Farbenlehrstreit Goethes mit Newton in wissenschaftsgeschichtlicher Sicht. Berlin: Akademie Verlag.

Frith, Simon \& Goodwin, Andrew \& Grossberg, Lawrence (1993): Sound and Vision: The Music Video Reader. London and New York: Routledge.

Hausheer, Cecilia \& Schönholzer, Annette (izd.) (1994): Visueller Sound: Musikvideos zwischen Avantgarde und Populärkultur. Luzern: Zyklop.

Helms, Dietrich \& Phleps, Thomas (izd.) (2003): Clipped Differences. Geschlechterrepräsentationen im Musikvideo. Bielefeld: transcript.

Jewanski, Jörg (2006): „Kunst und Synästesie während der Farbe-Ton-Kongresse in Hamburg 1927-1936“. V: Behne, Klaus-Ernst \& Kleinen, Günter \& de la Motte-Haber, Helga (izd.): Musikpsychologie. Inter- und Multimodale Wahrnehmung. Göttingen: Hogrefe.

Keazor, Henry \& Wübbena, Thorsten (2007): Video Thrills The Radio Star. Musikvideos: Geschichte, Themen, Analysen. Bielefeld: transcript.

Lampalzer, Gerda (1992): Videokunst. Historischer Überblick und theoretische Zugänge. Wien: Promedia.

Moritz, William (2004): Optical Poetry: The Life and Work of Oskar Fischinger. Bloomington: Indiana University Press.

McLuhan, Marshall \& Powers, Bruce R. (1995): The global village: der Weg der Mediengesellschaft in das 21. Jabrbundert. Paderborn: Junfermann.

Neumann-Braun, Klaus (izd.) (1999): Viva MTV! Popmusik im Fernsehen. Frankfurt: suhrkamp.

Neumann-Braun, Klaus \& Mikos, Lothar (2006): Videoclips und Musikfernsehen. Eine problemorientierte Kommentierung der aktuellen Forschungsliteratur. Berlin: Vistas.

Andreas Pütz (1995): Von Wagner zu Skrjabin: synästhetische Anschauungen in Kunst und Musik des ausgehenden 19. Jahrbunderts. Kassel: Bosse.

Rösing, Helmut (izd.) (2003): Spektakel, Happening, Performance. Rockmusik als Gesamtkunstwerk. Mainz: Villa Musica.

Schneider, Steven Jay (izd.) (2005): 1001 Filme - Die besten Filme aller Zeiten. Zürich: Olms.

Uka, Werner (1994): „Video“. In: Faulstich, Werner (izd.): Grundwissen Medien. Fink. München. 